\title{
Are there Seasonal Variations in the Incidence and Mortality of Esophageal Variceal Bleeding?
}

\author{
Jeong III Suh \\ Department of Internal Medicine, Dongguk University Gyeongju Hospital, Dongguk University School of Medicine, Gyeongju, Korea
}

See "Seasonal Impacts on the Incidence of Esophageal Variceal Hemorrhage: A Nationwide Analysis across a Decade" by Mohamed Tausif Siddiqui, Mohammad Bilal, Khwaja Fahad Haq, et al., on page 189-195.

Esophageal variceal bleeding is a major complication of portal hypertension and the leading cause of death in patients with liver cirrhosis. The major risk factors for esophageal variceal bleeding are variceal size, the presence of red color signs, and the severity of the liver disease. Recent advances in the diagnosis and treatment of esophageal variceal bleeding have improved the prognosis for patients with variceal bleeding. ${ }^{1,2}$ But the mortality rate is still $15 \%-30 \%$. $^{3,4}$

There have been several reports of seasonal variations on the incidence of esophageal variceal bleeding. Although seasonal differences are still controversial, many reports suggest that esophageal variceal bleeding occurs more often in winter. In France, deaths from esophageal variceal bleeding occurred with a clear annual periodicity, peaking in the winter (December and January), and hospitalizations due to esophageal variceal bleeding were more frequent in winter-spring with similar seasonal patterns. ${ }^{5}$ A study in Taiwan revealed a significant seasonal variation in the incidence of esophageal variceal bleeding, which most often occurred in February. ${ }^{6}$ A Korean study showed that the incidence of esophageal variceal bleeding was high in the spring (March and April) and low in the

Received: February 7, 2020 Accepted: February 25, 2020

Correspondence: Jeong Ill Suh

Department of Internal Medicine, Dongguk University Gyeongju Hospital, Dongguk University School of Medicine, 87 Dongdae-ro, Gyeongju 38067, Korea Tel: +82-54-770-8207, Fax: +82-54-779-8378, E-mail: sujungil@dongguk.ac.kr ORCID: https://orcid.org/0000-0002-3040-8766

(c) This is an Open Access article distributed under the terms of the Creative Commons Attribution Non-Commercial License (http://creativecommons.org/ licenses/by-nc/3.0) which permits unrestricted non-commercial use, distribution, and reproduction in any medium, provided the original work is properly cited. summer (July and August).

In this issue of Clinical Endoscopy, Siddiqui et al. ${ }^{8}$ showed that most hospitalization because of esophageal variceal bleeding occurred in December (99.3/day) and the least occurred in June (90.8/day) and that mortality was the highest in January (11.5\%) and the lowest in June (9.8\%). This study analyzed extensive data on seasonal incidence and mortality in 348,958 patients with esophageal variceal bleeding throughout the United States. Although this study was retrospective and based on the ICD codes, it appears to be a good example of the trend in seasonal differences.

The reason for the high incidence rate of esophageal variceal bleeding in the winter is unclear. However, some relevant factors such as physiological and neurohormonal effects of portal hemodynamics due to temperature changes and alcohol consumption have been suggested as causes. Peripheral vasoconstriction caused by cold temperatures in winter shifts the systemic blood flow to the visceral circulation, ${ }^{9}$ thereby increasing the portal blood flow and exacerbating the increase in portal pressure. Vasopressin reduces splanchnic blood flow and, therefore, reduces portal pressure. Sudden cold exposure in winter inhibits vasopressin secretion in the posterior pituitary gland, and decreased vasopressin in the blood increases esophageal variceal bleeding. ${ }^{10}$ In addition, hemodynamic seasonal changes in the portal vein can be influenced by meals, alcohol drinking, medications, and climatic factors such as day length, humidity, and barometric pressure. Further research should be conducted to analyze the causal factors.

In Siddiqui's study, ${ }^{8}$ the mortality from esophageal variceal bleeding was high in January. However, there are some limita- 
tions in the mortality analysis of this study. The progression of esophageal varices, the stage of cirrhosis, and combined systemic diseases such as heart diseases, diabetes, renal diseases, or respiratory diseases, were not shown. No mention was made of treatment options such as endoscopic band ligation, transjugular intrahepatic portosystemic shunt, and medications for esophageal variceal bleeding. If endoscopic treatment had been performed, the time of treatment would be important for mortality; no point was mentioned regarding this.

Prospective large-scale multicenter studies are needed to determine the seasonal differences in the incidence and mortality of esophageal variceal bleeding. In addition, research analyzing the causal factors is necessary.

Conflicts of Interest

The author has no financial conflicts of interest.

\section{REFERENCES}

1. McCormick PA, O’Keefe C. Improving prognosis following a first vari- ceal haemorrhage over four decades. Gut 2001;49:682-685.

2. Carbonell N, Pauwels A, Serfaty L, Fourdan O, Lévy VG, Poupon R. Improved survival after variceal bleeding in patients with cirrhosis over the past two decades. Hepatology 2004;40:652-659.

3. Reverter E, Tandon P, Augustin S, et al. A MELD-based model to determine risk of mortality among patients with acute variceal bleeding. Gastroenterology 2014;146:412-419.e3.

4. Kim YD, Cheon GJ, Kim MY, Suk KT, Baik SK, Kim DJ. Changes in the clinical outcomes of variceal bleeding in cirrhotic patients: a 10-year experience in gangwon province, South Korea. Gut Liver 2012;6:476-481.

5. Boulay F, Berthier F, Dahan MDC, Tran A. Seasonal variations in variceal bleeding mortality and hospitalization in France. Am J Gastroenterol 2001;96:1881-1887.

6. Yen FS, Wu JC, Wang LM, Kuo BI, Hu SC, Lee SD. Seasonal variation in the incidence of peptic ulcer and esophageal variceal bleeding in Taiwan. Zhonghua Yi Xue Za Zhi (Taipei) 1996;57:22-27.

7. Lee SH, Kim SJ, Jung SW, et al. Analysis of seasonal variation and risk factors of esophageal variceal bleeding in patients with cirrhosis. Korean J Gastroenterol 2002;40:386-393.

8. Siddiqui MT, Bilal M, Haq KF, Nabors C, Schorr-Lesnick B, Wolf DC. Seasonal impacts on the incidence of esophageal variceal hemorrhage: a nationwide analysis across a decade. Clin Endosc 2020;53:189-195.

9. Izzo JL Jr, Larrabee PS, Sander E, Lillis LM. Hemodynamics of seasonal adaptation. Am J Hypertens 1990;3:405-407.

10. Jasnic N, Dakic T, Bataveljic D, et al. Distinct vasopressin content in the hypothalamic supraoptic and paraventricular nucleus of rats exposed to low and high ambient temperature. J Therm Biol 2015;52:1-7. 